\title{
Exploration of Contributions of Women in Rural Development and Determinant Factors Influencing Their Participation, The Case of Agricultural Cooperatives in Ethiopia
}

\author{
Desalegn Fekadu Etefa \\ PhD Candidate, Ambo University: Institute of Business and Economics
}

\begin{abstract}
Women constitute about $50 \%$ of the world population and contribute about $75 \%$ to subsistence production. On the other hand, they earn one tenth of the world's income and they own one hundredth of the world's property including land. In Ethiopia, as in most parts of the world, women's role in the socio-economic activities is high, but they have less access basic resources than men do. Therefore, the enhancement of women's participation in all spheres of life has become a key issue in development discourses, which ratifies socio-economic development, cannot be fully achieved without the active participation of women. The primary economic activity of Ethiopia is agriculture which greatly depends on family labor where women play crucial role. Majorities of the rural populations are engaged in agricultural cooperatives, which is the business owned and controlled by the people to meet peoples' common requirements. Hence, this article explored women participation status and associated factors influencing their participation in agricultural cooperatives. Although the feminist theory proved that women and men have equal potential for individual development, the fruits that go to women are by far very low. The review identified that culture/customs, heavy work load and lack of time, lack of capital/credit, gender differentials, lack of education and training, lack of access to key economic resources, laws and rules, lack of access to property ownership, income generation and purchasing power as determinant factors influencing women participation in agricultural cooperatives. Therefore, to improve the situation, proposed interventions have to be made include: creating awareness through education and training to bring attitudinal change in the society, encouraging women participation, making different types of credit accessible, following the implementation of laws and rules as designed. For that matter, government organs at all levels and other stakeholders ought to work to attract more women to the cooperative members and also to bring them to the decision making positions.
\end{abstract}

Keywords: Agriculture; Contribution; Cooperative; Determinants; Participation; Women

DOI: $10.7176 / \mathrm{JCSD} / 61-03$

Publication date:September $30^{\text {th }} 2020$

\section{Introduction}

Participation is a development strategy that recognizes the need to involve vulnerable segments of the population in the design and implementation of their well-being policies. In this regard, women's participation refers to their active involvement in all fields of activity, such as economic, socio-cultural, environmental and political activities, and their role in decision-making and empowerment (Ademe \& Singh, 2016). Therefore, the enhancement of women's participation in all spheres of life has become a key issue in development discourses, that ratifies socioeconomic development cannot be fully achieved without the active participation of women in all activities, including decision-making at all levels of societies (Endale, 2012).

Women in the world play an important role in the development of both rural and urban areas. They are also believed to play a key role in helping their households and communities in achieving food and nutrition stability, generating income, and improving rural livelihoods and overall well-being (UN Women Watch Organization, 2017). In every country of the world, they are also the primary caretakers of children and elders. In fact, global studies show that women take the lead in helping the families adjust to new circumstances and obstacles when a society's economy and political organization shifts. Women are likely to be the main initiator of external assistance and play a major role in promoting and/or hindering changes in family life. Demographical study shows that the number of these much contributors represent half of the world's human resources (Rani \& Yadeta, 2016).

Of the different livelihoods, in countries where it is the main occupation of the poor as accredited by the International Development Community, agriculture is an engine of growth and poverty reduction. Among the different types of livelihoods, Co-operatives are believed to be one of the most successful solutions to improving livings across the globe. In contemporary times, where poverty abolishes the lives of billions of people around the world, cooperatives have arisen as an alternative economic resource. Cooperatives are a company owned and controlled by the people to meet the common needs of the people. For their mutual benefit, they finance and operate the business. This means that they are built on the leading idea that a group of people can achieve a goal that would be unattainable if it were to function alone by working together (Ruhul \& Mahin, 2014; Desalegn, 2019).

Cooperatives provide a means for farmers to join in an 'association' through which a group of farmers can achieve a better result, mostly financial, than go alone. This method is consistent with the theory of economies of 
scale and can also be related as a form of economic synergy, where "two or more agents work together" to produce a result that cannot be independently achieved by any of the agents (Adefila, 2012).

Amongst the many types of cooperatives, primary agricultural cooperatives play a dominant role in socioeconomic development of developing countries. In these enterprises, both male and female farmers pool their resources in certain areas of activities. This means that agricultural cooperative societies are organizations that seek to unite farmers in order to improve agricultural production by overcoming the challenges, shortcomings and odds of individual farmers collectively. Agricultural cooperatives as defined by Ibitoye (2012) are a mechanism through which services such as farm inputs, farm implements, farm mechanization, agricultural loans, agricultural extension, member education, marketing of farm produce members and other economic activities and services rendered are provided. Daily and efficient performance of these positions would promote the transition and sustainability not only of cooperatives, but also of agricultural and rural economic development.

Agricultural cooperative according to Alufohai and Ahmodu (2005) is a form of cooperative uniting agricultural producers for the production or other activities required by members (such as processing, marketing, production or supply of means of production). Similarly, Safarishali (2010) suggested that agricultural cooperatives are associations that pool purchases, storage and distribution of farm inputs to their members by taking advantage of discounted volumes and using other economies of scale. Agricultural cooperatives allow farmers to realize economic benefits that they would otherwise not be able to achieve on their own.

Agricultural cooperatives therefore play a crucial role in alleviating high transaction costs and market failure issues by providing services ranging from offering credit and modern inputs to generating market opportunities and selling products to members. This suggests that cooperatives have a great deal of potential to empower economically weak women and men by strengthening their collective bargaining power on the market, thus reducing the challenges they face on the market and allowing them to exploit enhanced market opportunities.

Cooperatives can help farmers to improve product and service quality and reduce risks; through building individual ability, they help improve the employment, leadership skills and overall socio-economic status and resilience of members (World Bank, 2009; Alkali, et al., 2018).

As a result, International Institutions, Governments and Non-Governmental Organizations are supporting the development of agricultural cooperatives and cooperative unions as a juncture for empowering vulnerable male and female smallholder farmers to secure sustainable livelihoods. Agriculture activities in developing countries rely heavily on family work, where the women's assignment is very high (Rani \& Yadeta, 2016).

In Ethiopia, the share of the agricultural sector to the country's development is enormous, where the contribution of women is substantial (MoFED \& UNICEF, 1994 cited in Yohannes \& Endale, 2014). Cooperatives in Ethiopia are primarily economic institutions performing economic functions, contributing a great deal in basic needs, especially for the vulnerable, in order to enable them to escape from poverty.

Irrespective of this fact, cooperative membership in Ethiopia is generally very low. According to Bernard \& Spielman (2009), just $9 \%$ of smallholders were members of agricultural cooperatives and only $40 \%$ of rural households had access to cooperatives within their communities. Even in areas where cooperatives operate, only about $17 \%$ of households have been reported as members (Federal Cooperative Agency (FCA, 2006). Of these figures, the number of female members is less than half of the male members as of 2016, regardless of their proportion of the country's population (FCA, 2016 cited in Amene \& Yadessa, 2018).

The low level of active participation and under-representation of women in decision-making and leadership is now one of the most important gender issues in cooperatives. As Awotide (2012) points out, women, especially in developing countries, including Ethiopia, are confronted with formidable constraints that hinder their active participation in cooperatives.

Moreover, compared to males, due to differential gender norms and interactions, women have a lower socioeconomic status, which restricts their prospects for access and inclusion in formal groups. This is therefore an indication that, given their important contributions to the lives of their families and communities, women are deprived of equal access to productive resources, markets and services (FAO, 2010). This is the opposite of the feminist theory, which argues that women and men have equal potential for individual development by looking at the many differences between the genders.

Feminist theory is that gender inequality is created by reducing access for women and girls to civil rights and the distribution of social resources, such as education and employment. This condition is primarily based on the socially constructed culture of the patriarchy that prolongs inequality between the two sexes (Enyew \& Mihrete, 2018).

Broadly speaking, women in Ethiopia have suffered multiple deprivations that have undermined their anticipated pivotal role in the social, cultural, economic and political spheres of life of society at large. This is due to many factors, including: lack of financial, educational and health services; low access to and control over resources and limited opportunities for employment; and inadequate involvement in power sharing and decisionmaking. In fact, the domination of men in different income-generating practices has a major impact on women's economic empowerment (Woldu \& Tadesse, 2015). 
All of the factors mentioned above are due to the effects of the masculine value system that has been practiced by society for centuries. Such factors have played a major role in deterring not only the enhancement of their wellbeing, but also the reduction of women's active participation in the overall socio-cultural and political and economic affairs of society at large in general and in agricultural cooperatives in particular.

\subsection{Objective of the Article}

To review the contributions of women in rural development and determinant factors influencing their participation in agricultural cooperatives in Ethiopia

\section{Empirical Studies on the Role and Status of Women Participation in Agricultural Cooperatives 2.1 The Role of Women in Agricultural Cooperatives}

As mentioned early, women have a major and vital role to play in the development of agriculture and allied sectors. Nonetheless, the nature and extent of women's involvement in agriculture vary greatly from region to region. However, irrespective of these differences, women are frequently involved in various agricultural activities.

Women make up half the world's population and are the guardians of the other half. Women's work benefits their families and communities as mothers and employees and growers (World Bank, 2019). Since agriculture is the backbone of developing countries, the role of women in this field is dominant. Real world conditions mean that rural women play a crucial role in ensuring food and economic security for their households (Gobezie, 2010; FAO, 2011b; CSA \& ICF, 2012). This means that they are practically involved in every sector of the economy.

Particularly in agricultural economic activities, as the global experience verified, women do 85 percent of weeding, 60 percent of harvesting, 50 percent of caring livestock, 50 percent of planting, and 30 percent of plowing (Lentisco \& Alonso, 2012). In addition, rural women do 95 percent of domestic work. Therefore, particularly in the developing part of the world, women are considered the backbone of the economy, according to Bezabih (2008). About $80 \%$ of economically active women are working in agriculture in most sub-Saharan Africa, and $70 \%$ are involved in food production (Assefa \& Tadesse, 2012).

In addition to providing much of the world's food, women have primary duty in society's daily lives. In line with this specific approach, rural women perform various labor-intensive work, such as producers, poultry ranchers, caregivers and cookers, childbirth and breastfeeding, food processing and distribution and other household chores in relation to children's education, housekeeping, family economy and management, firewood gathering, water fetching and weaving carpet used every day by their households. Furthermore, weeding, hoeing, grass cutting, digging, picking of cotton sticks, separation of seeds from fiber, holding of livestock and other related activities such as milking, milk processing, preparation of ghee, so on are women's role (Anonymous, 2003c cited in Tesfaye, 2015).

As discussed so far, rural women have many roles, and they have different responsibilities and knowledge from those of men. As a result, they play a major role in decision-making on family meal preparation and diet, and take steps to protect children's health and wellness. The contribution of women to the transition from pre-literate to literate culture is equally undeniable. They also provide basic education for children to promote the environment. It is the mother in the family who most often encourages children of both sexes to attend and stay at school. The role of women is at the front end of the family improvement chain, as well as the community's long-term ability (Harun, 2014; Tesfaye, 2015).

Women, especially in developing countries, are not only a source of labor for agricultural production, but also bear most of the burden at home (domestic work and childcare). In rural areas, women spend 53 per cent of all workloads and 20 per cent more time on jobs than men (Akpinar et al., 2004). Rural women split their time between agricultural and domestic activities and spend about 16 hours a day in these jobs (Tesfaye, 2015). They also have a key role to play in the development of rural society.

As far as the contribution of women in Africa is concerned, as in other parts of the world, their role in agriculture and rural society is fundamental to agricultural and rural development. Agriculture is therefore important for the national economy and as a source of employment in Africa. According to the FAO (1995) report cited in Tesfaye (2015), some $73 \%$ of the rural population is in rural areas of Africa, which consists of small farmers. Thus, women are the backbone of the rural economy in sab-Saharan African countries in particular. In these countries, almost half of the agricultural labor force is employed, $60 \%$ is engaged in the business, and the bulk of Africa's food is processed (Manuh, 1998; FAO, 2011b). In Ethiopia, too, where the share of agricultural sector accounts for about 40 per cent of national GDP, 90 percent of exports and 85 percent of jobs, there is an enormous contribution by women in the sector (MoFED \& UNICEF, 1994 cited in Yohanes \& Endale, 2014).

Of the different types of economic sectors, it is basically assumed that women's participation in agricultural cooperatives is also important for other developmental parameters in general and for sustainable cooperative growth in particular. The participation of more women in economic activities has contributed to a more integrated production process for both food and cash crops. Agricultural cooperatives can also be an effective means of empowering women in rural areas and helping them to resolve the constraints they face in accessing education, 
knowledge and information, as well as productive assets. It also strengthens the social role of the cooperatives themselves, provides a secure environment for women to increase self-confidence, bargaining power and employment, and encourages women to exercise political leadership.

Women's participation in Ethiopia is estimated to be between 45 and $75 \%$, especially in crop production (Bill \& Melinda Gates Foundation, 2010). Women are both producers and procreators, and they are also active participants in the social, political and cultural activities of their societies, with 70-80 per cent of agricultural labor being carried out in Ethiopia by women and 40-60 families headed by women.

Women in Ethiopia, however, seldom have access to resources that would make their work more efficient. If women had the same access to agricultural services and inputs as men, growth on women's farms could have increased by $20-30 \%$, reducing the number of hungry people in the world by 100-150 million (Swanson, 2002 cited in Alemu, 2016).

\subsection{The Status of Women Participation in Agricultural Cooperatives}

Status of women is their position or rank in comparison to others, typically compared to that of men; which can be measured in terms of educational attainment, jobs and remuneration, type of work, access to services and benefits, opportunities to take part in decision making and politics (Haregewoin \& Emebet, 2003).

In this context, empirical evidence shows that women contribute to the country's GDP by engaging in a variety of activities, but lack access to resources that limit their status. As the report presented by CSA \& ICF (2012) indicates, out of the total number of female primary workers, 55 per cent were agricultural workers and 24 per cent were cultivators. Nevertheless, only 12.8 per cent of the operating assets were held by women, reflecting the gender disparity in land tenure ownership in agriculture. In comparison, there is a concentration of women's operating assets (25.7 per cent) in the marginal and medium ownership groups.

Because cooperatives are people-owned and controlled enterprises that meet people's common requirements, the active participation of both men and women are a necessary condition for sustainable cooperative growth. In this regard, the idea of women's participation is an important analytical tool in the preparation, management, monitoring and assessment of development programs. The active participation of women (the invisible workforce) would make the cooperative economically and politically powerful. Active participation from the cooperative context means that participants are active in all the activities of the cooperative, including social, economic, planning, decision-making, execution and financial and management control (Birhanu, 2006). International law also has structure gender equality as part of global concern on human rights and basic freedoms for social, economic and political rights (Almaz, 2007; USAID, 2012).

Democratic Member Regulation is one of the concepts of the ICA Declaration on Cooperative Identification. ILO Recommendation No. 193 (2002) specifically refers to women's participation in cooperative decision-making, proposing that 'strong consideration has to be given to that women's participation in the cooperative movement at all levels, especially at the management level.' In this regard, cooperative legislation in a number of countries demonstrates that it is not a matter of discriminating against women, but of looking closely at fact, that it inhibits women's participation in decision-making. In reality, in addition to women's limited access to educational and training facilities, they are hampered in taking on leadership roles and as a result; they lack the necessary expertise, knowledge and skills required.

According to the report of the Federal Democratic Republic of Ethiopia (FDRE) study on the implementation of the AU Solemn Declaration on Gender Equality in Africa (2006), the majority of women in Ethiopia have low status compared to that of other African countries. Women have been denied equal access to education, training and employment opportunities, and their participation in policy formulation and decision-making processes has been limited. In Ethiopia, women make up about 50 percent of the population and contribute about 50 percent to subsistence production. However, in every aspect of their lives, women are subject to gender discrimination in economic, social, cultural and legal dimensions than any other women in any part of the world (Ademe \& Singh, 2015).

Most developing countries have a defining preference for males and give access to all privileges and freedoms for males. For example, most power and decision-making jobs are performed by men, while those that are tiresome, repetitive and take a lot more time and energy are women's responsibilities (Haile, 2009). In these countries, including Ethiopia, women carry a disproportionate burden, not only denied credit for their work where credit is due, but also denied freedom and dignity. Women often lack decision-making power in the home and society, as well as access to and control of productive resources. In addition, women are subject to variety diverse traditional practices such as female genital mutilation, early marriage and rape (ADB, 2004; World Bank, 2005).

Women are known to produce up to $80 \%$ of the food in Africa. Nonetheless, as far as agricultural inputs and services are concerned, the share that will go to women is limited and they earn just $7 \%$ of extension services, less than $10 \%$ of the credit given to small-scale farmers and own merely $1 \%$ of the land (Lentisco \& Alonso, 2012). They are often engaged in subsistence agriculture and unpaid farm work and are excluded from more lucrative agricultural opportunities such as cash crop production (ILO, 2009). In most African countries, women remain 
under-represented as workers, representatives and, for particular, leaders. Even the proportions of the two sexes entering small businesses as cooperatives indicate a wider gap. For example, cooperative research in Africa (Bezabih, 2008) reveals that only 18 per cent of the cooperative members are women (ICA, 2001). However, as regards the estimate of the Federal Cooperative Agency (FCA), of a total of 14,902,340 primary cooperatives, male members are 10,684,557, while 4,217,783 are female members (FCA, 2016, cited in Amene \& Yadessa, 2018). It shows that the number of female members was below half of those of the male members.

Given the tremendous contribution made by women to their livelihoods, food production and national economies, it has not been translated into greater access to resources or decision-making powers. As a result, 70 per cent of the world's women remained among the poorest of the poor (Lentisco \& Alonso, 2012). It illustrates how diverse and important roles women have not been accredited, resulting in lack of their fair share of the nation's wealth. As a result, most women are concentrated in the informal sector of jobs as housewives, bar owners, groomers (cleaners) and prostitutes (FDRE, 2006).

As a result, women in Ethiopia have a poor status in society. Women, compared to men, have unequal access, control and possession of key productive assets such as land, credit, knowledge and services. In 2005, only 18.6 per cent of rural landholders were women, only 9 per cent had access to agricultural extension services and only 12 per cent of those who had access to agricultural credit were women (Ministry of Women Affair (MoWA), 2005). Consequently, empirical evidence shows that women generate a third less per unit of land than male farmers due to gender barriers to input-use and access to agricultural extension services (Gashaw \& Goshu, 2017).

In fact, women have been denied equal access to education, training and employment opportunities. Due to this fact, women account for only 23.9 per cent of the technical and skilled industries, most of who work on tiresome, low-paid and unpaid jobs. Rural women have much poorer access to school and training facilities and therefore often lack the skills required for active participation in cooperative activities (CSA, 1999).

There are varieties of factors that affect women's participation in cooperatives; these factors as listed by the International Cooperative Alliance (Nippierd, 2012), which hinder active participation of women in cooperatives. The main contributors to women's low participation in cooperatives are deep-rooted socio-cultural norms and traditions that place women and girls in a much lower position relative to men and boys. Dominant gender expectations, assumptions and behaviors form ties of gender power at the family, group and institutional levels. Those affect women's social and economic capacities and incentives to participate as men. Usually, men and boys are supposed to be self-reliant, household heads, the primary household income earner, decision-makers, and civic officials. In contrast, women are believed to be mothers, caretakers of all household domestic duties and caregivers under the authority of male figures, second in command, and regarded as docile and submissive (UNFPA, 2008; Woldu \& Tadesse, 2015).

Several studies have shown that social practices control, communicate and transform human beings. Cultural and religious problems are among the factors that impede the participation of women. This is wonderfully illustrated by words like "women inside," which means that some of them are not speaking in front of people. Traditions of men managing and addressing financial issues, illiteracy, and family size are considered to have inferior skills, and social pressures make it difficult for women to play an active and visible public role (Endale, 2010).

Besides, the types of business cooperatives that deal with cash crops, which tend to be male, are another consideration and male opposition to women's participation. Strong domestic workload, which they have to do, leaves them short of time to join cooperatives the other hindering factor. In general, the patriarchal socio-cultural, economic and social rules and regulations in place prevented women from enjoying their labor, which will be addressed in the next section.

Women's involvement in agricultural cooperatives is generally assumed to be essential for sustainable cooperative growth. The inclusion of more in economic activities has resulted in a more integrated production process for both food and cash crops. It is generally assumed that women's participation in agricultural cooperatives is important for sustainable cooperative development. The involvement of more women in economic activities has been found to result in a more integrated production process of both food and cash crops. Agricultural cooperatives can also be an effective means of empowering women in rural areas and helping them to resolve the constraints they face in accessing education, knowledge and information, as well as productive assets. It also strengthens the social role of cooperatives themselves, provides a secure environment for women to increase their self-confidence, bargaining power and employment and encourages women to exercise political leadership.

In summary, the status of Ethiopian women is low where they are generally poorer than men because they earn less; they are less educated; they are increasingly becoming heads of households, with no resources to support their dependents; they do not have due recognition for their work contribution, especially in agriculture, and they do not have the power to make decisions that can be discussed in the next section.

\subsection{Factors Influencing Women Participation in Agricultural Cooperatives}

The exclusion of women from socio-economic participation and decision-making processes has been a legacy of 
human history. Even when democracy was established in ancient Athens in the $5^{\text {th }}$ century BC, women were excluded from political participation and decision-making. The women of Athens did not have the right to vote or engage in the democratic process, nor did they consider them to be citizens (Khadar, 2013). Even in European countries, women were neither entitled to political participation nor active in decision-making and public affairs until the beginning of the $20^{\text {th }}$ century. Women's franchise rights are therefore not accepted in the first phase of democratization (1828-1926) in many European countries (Hague \& Harrop, 2014).

As far as the case of Ethiopia is concerned, the status of women in socio-economic development is very recent and their participation is still very low. For a variety of reasons, however, Ethiopian women tend to be hesitant to become active participants in agricultural cooperatives. Such factors are usually classified as socio-cultural, economic, educational and training factors and factors related to laws and rules, which are to be addressed in depth as follows.

\subsubsection{Socio-Cultural Factors}

In the context of Ethiopia, there is a traditional belief that, women are made to take care of children and do kitchen work rather than take part in activities outside the home. As a result, there is a division of labor between men and women, which mean home tasks, suitable for women and out - of-home activities belong to men. Women are overburdened with various household tasks, such as cooking, taking care of children, washing, and so on. All these practices put women at work in the home and impede their participation in the development programs of their countries.

\section{i. Culture/ Customs}

Traditions tend to emphasize women's primary roles as mothers and housewives in many countries and to confine them to those roles. A traditional solid, patriarchal value system promotes gender segregated roles and 'traditional cultural values' combats the development, advancement and involvement of women in any socio-economic and socio-political process. Societies all over the world are governed by the ideology of the thought of the position of a woman. According to this ideology, women should only play the role of working rather than talking of any rights (Shvedova, 2002).

In many cultures of the societies, women are portrayed as frail and incapable of making small decisions. This was projected and compounded over the years by male-dominated institutions and patriarchal structures that internalized the idea that women were inferior. With the constant reinforcement of the notion that women are inferior in every way, it has become difficult for women to seek their political rights as active participants (Kassa, 2015).

In addition, in most countries, there are structured stereotypes that women can do and cannot do. The study conducted by Idrisa et al., (2007) reveals that culture/customs was the main barrier to women's participation in agricultural cooperative activities. In some cultures, women are prohibited from doing business independently or without their husband's permission. This presents a serious challenge to participation in cooperative activities. They may not be employed for certain jobs, nor may they be allowed to attend and speak at meetings. While, in some cases, the legal rights of women may be laid down in the cooperative constitution, they may not always be followed or superseded by customs. The pervasive myths regarding women's reproductive and domestic roles constitute and put them at the periphery of the cooperative business world. According to Yigremew (2001), some of the cultural values working against women are limited participation in cooperatives, the smaller size of women in cooperatives, the gender bias of local officials, and the lack of access to vital resources and services and so on.

Religion is also another important source of cultural belief in most countries. Religious rules and customs may also hinder the participation of women in cooperatives (Haile, 2009). There are claims regarding women's inferiority to men across all dominant religions, and religion has long been used to exclude women from financial, political, or religious life around the world (Kunovich, et al., 2007). Most of the world's religions are differently conservative or patriarchal of the idea of the place of women, both in the Church hierarchy and in society.

Ethiopia is a patriarchal society that keeps women in a subordinate position, using religion and culture as an excuse. For many years, these arguments have been enabled by laws and legislation that perpetuate the patriarchy and the subordination of women. This has contributed to and sustained inequality between men and women, the division of labor, the share of income, the law and the economy, the manner in which households are interrelated (Haregewoin \& Emebet, 2003).

Consequently, the exclusion of women from religious institutions and religious leadership may have a negative impact on the status of women in society and may restrict their opportunities in politics and public life. In most religions, power and authority are believed to belong divinely to men, and thus to subjugate women. Women are thus encouraged to play subordinate positions, since they have a position in the kitchen and men are decision-makers. There are concerns regarding women's inferiority to men across all prevailing religions, and historically religion has long been used to exclude women from social, political aspects or religious life around the world (Kassa, 2015). Religious is therefore one of the cultural beliefs in many cultures that exclude women from the mainstream of leadership. 


\section{ii. Gender Differentials within Rural Labour Markets}

The family is the core institution of the patriarchy, an important principle for understanding gender inequality (Kate, 1970, cited in Gashaw \& Goshu, 2017). It literally means "the law of the father;" more generally, it refers to a society controlled and dominated by men over women. This is existent in the majority of African communities. Giving men a higher social status than females has entered into public life, which is reflected in state activities. The biggest psychological tool available to man is the length of time they have enjoyed dominance over women, who have taken it for granted that they often tend to stereotyping women and justify their subordination (Damilola, 2010).

Due to lack of representation in the boards of directors, the executive committee, where decisions are taken because of the barriers set out above, women have no impact on cooperative activities. Women lack the necessary powers and are forced to play a passive role, while men usually control decision-making activities within cooperatives. Several studies show that women hesitate or refuse to enter mixed cooperatives because they want to escape male domination. Given the democratic principles and values that promote equity and equality, gender imbalances do exist. Women's low level of active participation and under-representation in decision-making and leadership are among the most significant gender issues in cooperatives today (Ekesionye \& Okolo, 2012).

In addition to the differences in male and female labor participation rates noted earlier, there are also significant gender differences in job trends in labor markets for a number of reasons across cultures and regions. Most notably, as a result of household and child-rearing, women are not only much less likely to be part of the workplace; they are also much more likely to be part of the military. Perhaps notably, women are not only much less likely to participate in the labor force as a result of household and child-rearing; those who do are also much more likely to engage in self-employment rather than pay higher wages. Due to child care obligations, economically active women often leave the labor market and thus gain less work experience.

As a consequence of time constraints, women are also more likely to work in part-time jobs and informal contracts that pay less and/or provide fewer benefits, but provide more flexibility. Females are also more involved in some processes or functions of the supply chain (e.g. packaging, post-processing). Segregation into lowtechnology occupations limits opportunities to generate new skills and capabilities, hindering future career growth and growing prejudice against these sectors as low paid and low-levels of education and experience. Finally, there is a well-documented pay gap in urban labour markets that is likely to exist in rural labour markets, and that women are paid less even for similar jobs and comparable levels of education and experience.

\section{iii. Heavy Work Load and Lack of Time}

Continuing uneven distribution of family care duties between males and females means that women spend far more time than men at home and at workplace. Studies have consistently shown that women pay a "motherhood tax" across fields, not only in terms of time, commitment and medical care for pregnancy and children, but also in terms of the far greater maternal presence required for breastfeeding and the persistent propensity of women to have a larger share of childcare while the child grows (Kassa, 2015).

Rural women sometimes work long hours in developing countries. They also have the primary responsibility for the family. It includes the supply of water and food often long distances, and the need for cooking, cleaning and washing. Women also bring up children and take care of their families. They also aid in wedding and funerals, hard work in fields that are often located far from their home. Gender differences become apparent as we look at the workload of women. It is estimated that women provide 85 to 90 percent of the time spent on household food processing and preparation in a wide range of countries (Fontana \& Natalia, 2008; Wrangham, 2009). Based on the layout and size of the household, these activities may be extremely time consuming. Time allocation studies have shown that women function considerably more than men if treatment is included in the calculations (Ilahi, 2000; Kes \& Swaminathan, 2006; Budlender, 2008).

Besides the activities referred to in Lentisco \& Alonso ( 2012), rural women do, in total, 95 per cent of domestic work, 85 per cent of weeding, 60 per cent of harvesting, 50 per cent of livestock farming, 50 per cent of planting and 30 per cent of plowing. Generally, like women in other parts of the world, they are typically in charge of domestic chores in Ethiopia, while men are responsible for activities outside the home and men also spend their free time socializing outside the home, while women take care of the household, making it difficult for them in economic activity. Such circumstances intensify the problems that women face. Given all this, their contribution is often unrecognized and largely overlooked in most countries.

\subsubsection{Economic Factors}

Historical experience of inequality puts women in an economically disadvantaged role. Women are generally less able to participate in economic opportunities than men as they face a workload that men do not have. In most cultures, women are responsible for the majority of household and child-rearing tasks, as well as the rearing of small livestock, although the standards vary for culture and overtime. The extra workload is unpaid and restricts women's ability to participate in income-generating activities, which often require a minimum of fixed time before they are profitable. Moreover, the essence of jobs, such as caring for children and elderly household members, causes women to stay close to home, thereby reducing the possibility of working for a paycheck. Time scarcity 
causes many women to start up cottage industries, such as handicrafts, which are often characterized by low returns and minimal capacity for expansion (Lanjouw, 2001). All of these; place women in a state of lack of economic opportunities, which is one of the biggest obstacles to women's involvement in socio-economic activities that can be expanded on in the ongoing sub-themes.

\section{i. Lack of Working Capital/Credit}

Inadequate financing remained a major problem for agricultural production. This is because capital is the most important input into agricultural production, and the availability of capital remains a major problem for smallscale farmers, who account for the bulk of the nation's agricultural produce. The lack of capital resources limits the opportunities for women in particular to become members of cooperatives where they are involved membership fees have to be paid. It will also lessen their incentives to use cooperative facilities, buy crops, fertilizers, pesticides, milk and household goods. However, the movement of men to cities and other countries also means that children and their parents are mostly women behind them. Among the economic limitations for women's groups and cooperatives are the lack of financial capital, the small business ideals of the cooperative enterprises which do not allow employment of qualified staff, difficulties in obtaining external financing without collateral security, and lack of business skill (Woldu \& Tadesse, 2015).

\section{ii. Lack of Access to key Economic Resources}

Throughout primitive society, the role of women was much greater than that of men. In this system, where the position of men was limited to clearing the land, women were the dominant figures in farming practice. They prepare the soil, sowing, weeding, harvesting, threshing and transporting agricultural products. In addition, rural women have played a significant role in the cultivation of livestock and are active participants in the management of livestock, such as feed supplies, milking and the care of animals. Women are both consumers and procreators and are also active participants in the social, political and cultural activities of their families (Boserups, 1970, cited in Tegegne, 2012).

Contrarily to this, the study showed that rural women in developing countries have less property rights, have no role in economic production, and have remained economically vulnerable (Women Affairs, 2004 cited in Berhan, 2010). Rural women have different levels of access to power over natural or cultural, human and financial resources, as well as public services and facilities. Women are deprived of direct ownership of resources in the patriarchal system of society (Ayferam \& Fisha, 2015).

Land ownership is the main requirement for cooperative membership, of the key economic resources. It is the main resource for human beings in general and agricultural communities in particular. Land is not only a productive resource and a source of material wealth, but also a source of stability, prestige and recognition. Worldwide, only 1 to 2 per cent of women holds titled land and is often denied the right to inherit those properties (Harun, 2014).

Many women, married or female, have limited access to and ownership of land due to traditional practices that presume male control and ownership, despite new land certification policies in Ethiopia that identify women and men as equal owners (Kumar \& Quisumbing, cited in Woldu \& Tadese, 2015). One of the study described landownership as the most significant determinant of cooperative membership in Ethiopia (Bernard \& Spielman, 2009).

Women's right to land originated in Ethiopia during the Derg regime in 1974. At that time, women were actively involved in the political arena. They had their own mass body, the Radical Ethiopia Women's Association (REWA). That land rights were also admitted in the rural land declaration of the Dergue regime (Mamo, 2006). The current government is also in a similar position to that of the Dargue regime on land rule. Women have the right to possess, maintain, regulate, use and transfer land. Women have equal rights with men with respect to the use, transfer and ownership of land. Women also receive equal care in the inheritance of property rights (Hagos \& Holden, 2013). The truth of the yield, however, does not fit the blueprint of a strategy on women's rights.

\section{iii. Lack of Property Ownership, Income Generation and Purchasing Power}

In the past, women were not owners of the means of production even when they were inherited into job areas. In the last one and a half decades, urban women have had access to work that does not require formal education. Females are now filling jobs in the construction industry and manufacturing, as well as in sales and marketing services.

On the other hand, most rural women do not have an independent budget, but rely at their husbands for their income, even though they engage in different income-generating activities. After the husband gives them the family's monthly budget, they use the small amount of money to fulfill other family needs that could not be covered with what their husbands give them. Mostly, this portion is important for women to buy household goods to support the family. A woman may be able to use some cash for her own personal use if she finds it necessary, but the circumstances are such that there is scarcely enough food for household use during the season until the coming harvest. Therefore, women rarely spend on themselves or their children without the permission of their husband and even then only on special occasions such as holy days (Brown \& Davis, 2014). What is shocking is that while women do a great job in both the triple position (production, reproduction and community management) they do 
not have the right to make a decision and even their husbands do not consult them on the distribution of the products. The United Nations statistically shows that women make $2 / 3^{\text {rd }}$ of the available work in the world and earn $1 / 10^{\text {th }}$ of their income (Lalremruati, 2016).

\subsubsection{Lack of Education and Training}

Knowledge is needed to enable citizens to take an active part in the management of cooperatives. In this regard, women in developing countries lack basic education that is required for further training. Women can, however, are prohibited from engaging in education and training programs for other reasons such as not being allowed to travel, lack of time due to domestic workload or carrying out additional tasks. In line with this, the United Nations statistical report shows that women make up $2 / 3^{\text {rd }}$ of the illiterate people of the world and therefore gain less than $1 / 100^{\text {th }}$ of the world's wealth (Lalremruati, 2016). More evidence shows that the low level of education of women is one of the most important factors leading to the participation of women in cooperatives (Idrisa et al., 2007; FAO, 2011b).

\subsubsection{Cooperative Laws and Rules Related Factors}

In this regard, numerous studies show that cooperative rules, legislation and by-laws still discriminate against married women by demanding that the requirement of membership be the head of household (Oxfam International, 2013). In some parts of the regions, most cooperatives have 'only one member per household' as their membership rule, which has resulted for female household heads being more likely to be members than married women (ibid). Therefore, female heads of household are more likely to join than married women because they are less limited in their autonomy and have greater freedom and access to information to join those classes. Married women frequently feel excluded from male-dominated cooperatives because of male-dominated rules governing cooperative membership. As such, the advantages of access to input facilities, participation in training and knowledge sharing are refused. In practice, it is assumed that men will engage in such activities and pass on the information and knowledge they have acquired to their wives. Nevertheless, in fact, there is often no "crossing" because, in general, men and women do not have the same priorities when it comes to living decisions (Aregu et al., 2010 pp. 36).

In general, obstacles women face changes according to individual and social group characteristics such as social and educational status, age and place. One study found that older, wealthier, more educated, pregnant, female householders are more likely to be members of agricultural cooperatives than other women (Oxfam International, 2013). Such women have less household responsibilities, less time constraints, greater access to assets and resources, and a wider range of informal and formal community memberships. Due to a variety of factors, such as cultural traditions that limit autonomy and bargaining power, married women face unequal access to and leverage over key productive assets.

\section{Conclusion}

Women contribution to the country's socio-economic development is multifaceted. Hence, their active involvement in all developmental perspectives is highly pivotal. This would not be out of place to recognize the socio-economic status of women as a measure of the country's development, as women make up half of the population. A cooperative considered as a way of empowering rural poor women who do not have access to cooperative management, basic resources and different service benefits.

This seminar paper was primarily intended to assess women's role in agricultural cooperatives, to analyze the status of women participation in agricultural cooperatives and to identify factors determining women's participation in agricultural cooperatives societies. In connection with this, the seminar identified that women in Ethiopia face multiple types of deprivation in order to contribute to their task in all disciplines in general and in agricultural cooperatives in particular.

Although governments and many stakeholders have been realized in achieving gender equality, attempts in most parts of the world to ease the exploitation and subordination of women are unsuccessful. Actions have been taken by governmental and non-governmental organizations, women's groups, associations and feminist movements. However, the emphasis is mostly on the public sphere rather than the private sphere. Laws, legislation, reforms, education and training are mostly offered or enforced in the workplace. The emphasis given to the public sphere to provide men and women or boys and girls equal opportunities and enjoyment of rights is not given to the domestic sphere to accompany it with rewards and benefits.

Accordingly, the main constraints that inhibit women from participating in cooperatives factors are usually classified as socio-cultural, economic, educational and training factors and factors related to laws and rules. Such factors are: Culture/customs, which is the negative attitude of the society towards women, gender differentials within rural labor markets, work load in the house and lack of time that limited mobility, lack of capital/credit, lack of access to key resources, lack of property ownership, income generation and purchasing power, lack of education and training leading to lack of skill, awareness and information, culture, information, cooperative laws and rules related factors that discriminate against married women by demanding that the requirement of membership be the head of household are the most important factors contributing to the inactive participation of 
women in agricultural cooperatives.

\section{Proposed Interventions}

Therefore, in order to improve women participation status in the agricultural cooperatives, special consideration should be given to increasing their involvement in the cooperative movement at all levels. Cooperatives should strengthen and expand the involvement of more women in the cooperative sector in order to improve their livelihood. Hence, cooperatives should target on continuous education, training and information to all women to strengthen women's capacities and capabilities, resulting in their increased self-confidence and enabling them to participate fully in decision-making and assume leadership positions. Active, equitable participation of members, both men and women, is a necessity for sustainable cooperative development, which means active participation in the cooperative context is involvement of women in all the functions of cooperatives including planning, decisionmaking, implementation and financial and management control.

Cooperative promoters at all levels and other stakeholders should enforce the cooperative societies to incorporate women as a precondition for the functioning of the cooperative organization. Cooperatives should review their policies and plans periodically to ensure that they are gender sensitive. Gender integration in cooperative development is also essential because active and equitable participation of members, both men and women, is a necessary condition for sustainable cooperative development. Cooperatives will benefit from the under-utilized half of the world's human resources by enhancing women's productive capabilities. It is significant that the involvement of more women in cooperatives will broaden the scope of cooperatives and improves their social role by empowering them to decision-making level. Cooperatives should also consider designing and implementing training, family dialog, community conversation programs that bring attitudinal change in men so that they share the household responsibilities, since these are deep-routed cultural issues that need more awareness and behavioral changes.

\section{References}

Adefila, J. O. (2012). Spatial Assessment of Farmers' Cooperative Organizations in Agricultural Development in Gurara area of Niger state, Nigeria. Journal of Ecology and the Natural Environment. Vol. 4(2) pp. 51-57.

Ademe, G., \& Singh, M. (2016). Factors Affecting Women's Participation in Leadership and Management in Selected Public Higher Education Institutions in Amhara Region, Ethiopia. Ethiopia European Journal of Business and Management, 7, 31 .

African Development Bank (ADB) (2004). Multi-Sector Country Gender Profile.

Akpinar N, Talay I, Cos, Ceylan K, Gunduz S (2004). Rural Women and Agro Tourism in the Context of Sustainable Rural Development: A case study from Turkey. Kluwer Journal, 6: 473-486,

Alemu, G. T. (2016). Constraints Rural Women Farmers Face in Utilizing Agricultural Extension Services in Bure Woreda, North Western Ethiopia.

Alkali1, A., Gwary, M. M., Umar, A. S. S., Mustapha, S. B. \& Thlawur, P. (2018). A Review on Participation of Women in Agricultural Cooperative Societies in Nigeria. International Journal of Social Science and Humanities Research, Vol. 6, No. 1, 2018, pp. 22-31.

Almaz Woldetensaye (2007). Women's Access to and Control Over Land in the Current Land Administration System in Two Rural Kebeles in Ada'a Woreda of Oromia Region. MA Thesis, Addis Ababa University.

Alufohai, G. O. \& Ahmodu,J. (2005). Queue Management by Nigeria Agricultural Cooperative and Rural Development Bank (NACRDB) in Farm Credit Delivery. The case of Benin Branch, Edo State, Nigeria Proceedings of the $39^{\text {th }}$ Conference of Agricultural Society of Nigeria (ASN) Held at the University of Benin, Nigeria. $9^{\text {th }}-13^{\text {th }}$ October, pp. 300-303.

Aregu, L., Bishop-Sambrook, C., Puskur, R. \& Tesema, E., (2010). Opportunities for Promoting Gender Equality in Rural Ethiopia through the Commercialization of Agriculture. IPMS Working Paper 18.

Assefa, T. W. \& Tadesse, F. (2012). Women's participation in Cooperatives in Ethiopia. International Food Policy Research Institute (IFPRI), Ethiopian Strategy Support Program (ESSP II), Pp. 28.

Awotide, D. O. (2012). Assessment of Women's Participation in Cooperative Societies and its Determinants in Yewa North Local Government Area of Ogun State, Nigeria. Asian Journal of Agriculture and Rural Development, Vol. 2, (3), pp-12.

Ayferam, G., \& Fisha, A. (2015). Assessment of Rural Women's Participation in Agricultural Production: the Case of Awaro Kora Peasant Associations, Ambo District West Shewa Zone, Oromia Region. Inter. J. Polit. Sci. Develop, 3(1), 40-49.

Berhan, D. (2010). Women Empowerment through Saving and Credit Cooperatives. The case of Tigray Region, Mekelle University, Ethiopia.

Bernard, T., \& Spielman, D. J. (2009). Reaching the Rural Poor through Rural Producer Organizations. A Study of Agricultural Marketing Cooperatives in Ethiopia. Food Policy. 34 (1), 60-69.

Bezabih Emana, (2008). Current Status of Cooperative in Ethiopia, Cooperative Africa. 
Bill \& Melinda Gates Foundation (2010). "Accelerating Ethiopian Agriculture Development for Growth, Food Security, and Equity."

Birhanu Megersa. (2006). Gender Issues in Cooperatives in West Showa Zone. Ambo University.

Brown, J. C., \& Davis, R. C. (2014). Gender and Society in Renaissance Italy. Routledge.

Budlender, D. (2008). The Statistical Evidence on Care and Non-Care Work across Six Countries. Geneva: United Nations Research Institute for Social Development (UNRISD).

Cheng, S. J. A. (1999). Labor Migration and International Sexual Division of Labor: a Feminist Perspective. In Gender and Immigration (pp. 38-58). Palgrave Macmillan, London.

Central Statistical Agency (CSA) (1999). Federal Democratic Republic of Ethiopia Central Statistical Agency. Population censuses.

CSA \& International Classification of Functioning (ICF) (2012). Ethiopia Demographic and Health Survey 2011. Addis Ababa, Ethiopia and Calverton, Maryland, USA: Central Statistical Agency and ICF International.

Damilola, T. (2010). Women's Participation and the Political Process In Nigeria: Problems and Prospects. African Journal of Political Science and International Relations. 4, 75-82.

Desalegn Fekadu (2019). The Role of Multi-Purpose Cooperatives in the Economic Development in Ethiopia, the Case of Lalo-Assabi District (West Wollega Zone, Oromia Regional State). Research on Humanities and Social Sciences. Vol.9, No.21, pp 13-30.

Ekesionye, E. N., \& Okolo, A. N. (2012). Women Empowerment and Participation in Economic Activities: Indispensable Tools for Self-Reliance and Development of Nigerian Society. Educational Research and Reviews, 7(1), 10-18.

Endale, A. (2012). Factors that Affect Women Participation in Leadership and Decision Making Position. Asian Journal of Humanity, Art and Literature.

Endale, N. (2010). Participation of Women in Rural Cooperatives: Evidence from Gewane and Fentale Districts of Afar Region, Ethiopia. MA Thesis.

Enyew, B. E., \& Mihrete, A. G. (2018). Liberal Feminism: Assessing its Compatibility and Applicability in Ethiopia Context. International Journal of Sociology and Anthropology, 10(6), 59-64.

Federal Cooperative Agency (FCA) (2006). Annual Report on Cooperatives. Addis Ababa, Ethiopia.

Federal Cooperative Agency (FCA) (2016). Federal Cooperative Agency Annual Report. Addis Ababa: Unpublished.

FAO (2010). Cooperatives: A pathway to Women's Empowerment in Rural Areas, 16 ${ }^{\text {th }}$ International Day of Cooperatives.

Fontana, M. \& L. Natali. (2008). Gendered Patterns of Time use in Tanzania: Public Investment in Infrastructure can help? Paper Prepared for the IFPRI Project on 'Evaluating the Long-Term Impact of Gender-Focused Policy Interventions.

Food and Agricultural Organization (FAO) (2011b). The State of Food and Agriculture: Women in Agriculture: Closing the Gender Gap for Development. Rome, Italy: Food and Agriculture Organization of the United Nations.

Food and Agricultural Organization (FAO) (2012). Cooperatives: Empowering Women Farmers, Improving Food Security.

www.fao.org/gender/gender-home/gender-insight/gender-insightdet/en/c/164572

FDRE, (2006). The Implementation of the All Solemn Declaration on Gender Equality in Africa Addis Ababa.

Gashaw, S., \& Goshu, D. (2017). Determinants of Rural Women Empowerment in East Hararghe Zone, Ethiopia (Doctoral dissertation, Haramaya University).

Gobezie, G. (2010). "Empowerment of Women in Rural Ethiopia: A review of Two Microfinance Models." Praxis: The Fletcher Journal of Human Security XXV: 23-38.

Hagos, H. G., \& Holden, S. (2013). Links between Tenure Security and Food Security: Evidence from Ethiopia (Vol. 1288). Intl Food Policy Res Inst.

Haile Geberel Yekdem (2009). The Role of Cooperatives in Empowering Women: The Case of Mekaleya SelfEmployed Women's Savings and Credit Cooperatives, Thesis Paper.

Hague, R. \& Harrop, M. (2004). An Introduction to Comparative Government and Politics.

Haregewoin Cherinet \& Emebet Mulugeta (2003). A Profile on Gender Relations: Towards Gender Equality in Ethiopia. Swedish International Development Cooperation Agency. Harun,

M. E. (2014). Women's Workload and their Role in Agricultural Production in Ambo District, Ethiopia. Journal of Development and Agricultural Economics, 6(8), 356-362.

Ibitoye, S. J. (2012). Survey of the Performance of Agricultural Cooperative Societies in Kogi State, Nigeria. European Scientific Journal, Vol. 8(14) pp. 99-101

ICA (2001). Survey on Agricultural Cooperatives in Kenya.

Ilahi, N. (2000). The Intra-Household Allocation of Time and Tasks: What have We Learnt from the Empirical Literature? Policy Research Report on Gender and Development, Working Paper Series No. 13, World Bank: 
Washington DC.

ILO Recommendation No. 193 (2002). On the Promotion of Cooperative "Special Consideration should be given to increasing Women's Participation in Cooperative at the Higher Level.

Idrisa, Y. L., Sulumbe, I. M., \& Mohammed, S.T., (2007). Socio-Economic Factors Affecting the Participation of Women in Agricultural Cooperatives in Gwoza Local Government, Borno State, Nigeria. Journal of Agriculture, Food, Environment and Extension. 6 (2), 73-78.

International Labour Organization (2009). Cooperatives: A Path to Economic and Social Empowerment in Ethiopia, Coop in Africa, Working paper No.9, Geneva, Switzerland. International Labour Organization.

Kassa, S. (2015). Challenges and Opportunities of Women Political Participation in Ethiopia. J Glob Econ 3: 162. doi:10.4172/2375-4389.1000162.

Kes, A. \& H. Swaminathan (2006). Gender and Time Poverty in Sub-Saharan Africa. Chapter 2 in Blackden, C.M. and Q. Wodon. (Eds.). Gender, Time Use, and Poverty in Sub-Saharan Africa. WB. Working Paper No. 73, the World Bank, Washington, D.C.

Khadar, M. (2013). Women Political Participation and Decision Making in Hargeisa, Somaliland.

Kunovich, L., Paxton, P. \& Hughes, M. (2007). Gender in Politics. Annual Review of Sociology.

Lalremruati, A. (2016). Gender Role in the Livelihood Activities of Shifting Cultivation in Mizoram: A Case Study of Chawngtlai Village.

Lanjouw, J.O. \& P. Lanjouw (2001). The Rural Non-Farm Sector: Issues and Evidence from Developing Countries World Development 26: 1-23.

Lentisco, A., \& Alonso, E. (2012). On Gender Mainstreaming Strategies and Tools in Fisheries Development Projects: RFLP Gender Strategy and Lessons from the Asia-Pacific Region. Gender in Aquaculture and Fisheries: Moving the Agenda Forward, 117105.

Mamo Hebo (2006). Land, Local Customs and State Polices: - Disputes and Disputes Settlement among the Arsi Oromo of Southern Ethiopia Kyoto University - Japan Nakanishi printing co. Ltd- Japan.

Manuh, T. (1998). Women in Africa's Development: Overcoming Obstacles, Pushing for Progress. Africa Recovery Briefing Paper Issue 11. United Nations Dept. of Public Information.

Ministry of Women's Affairs (MoWA) (2005). "Gender Relations in Ethiopia: Final Report." Addis Ababa: Ministry of Women's Affairs.

Nippierd, A. B. (2012). Gender Issues in Cooperatives. ILO.

Oxfam International (2013). Women's Collective Action: Unlocking the Potential of Agricultural Markets. Oxfam International Research Report. Oxfam International, Oxford, UK.

Rani, D. L., \& Yadeta, D. B. (2016). Determinants of Women Participation in Primary Agricultural Cooperative Societies of Dendi District, Ethiopia. IJAR, 2(8), 380-384.

Ruhul, A. M., \& Mahin, U. M. (2014). Socio-Economic Impacts of Cooperative Societies: An Empirical Study. SOCRATES: An International, Multi-lingual, Multi-disciplinary, Refereed (peer-reviewed), Indexed Scholarly journal, 2(2), 179-193.

Safarishali, R., (2010). A Survey of the Activities and Performance of Poultry Agricultural Cooperatives of Tehran Province. M.A. Thesis, College of Agriculture, Isfahan University of Technology.

Shvedova, N. (2002). Obstacles to Women's Participation in Parliament.

Tegegne Messay (2012). An Assessment on the Role of Women in Agriculture in Southern Nation Nationality People's Region: The case of Halaba Special Woreda, Ethiopia (Doctoral Dissertation, Indira Gandhi National Open University).

Tesfaye, T. (2015). Rural Women Participation in Agricultural Activities and Household Managements in Ethiopia: a case Study of Delanta Dawunt District, North Wollo Zone. Afr. J. Agric. Sci. Technol, 3(7), 327-340.

Tewodros Biset Amene \& Atnafu Yadessa (2018). Determinants of Multi-Purpose Primary Cooperatives Marketing Performance in the case of West Hararghe Zone, Ethiopia. International Journal of Business and Management Invention (IJBMI). Vol.7, issue 10, PP-11-32.

United Nations Population Fund (UNFPA) (2008). Gender Inequality and Women's Empowerment. Ethiopian Society for Population Studies. In-depth Analysis of the Ethiopian Demographic and Health Survey 2005. Addis Ababa, Ethiopia: UNFPA. http://ethiopia.unfpa.org/drive/Gender.pdf

UN Women Watch Organization (2017). Un Information and Resources on Gender Equality and Empowerment of Women, http://www.un.org/womenwatch/

United States Agency for International Development (USAID) (2012). "Promoting Women in Cooperatives in Ethiopia: for Agricultural Value Chains Development." Report of Consultation held in Addis Ababa, January $25-26,2012$.

World Bank (2005). Wellbeing and Poverty in Ethiopia: The Role of Agriculture and Agency.

World Bank (2009). Gender in Agriculture. Source Book. Washington, DC: World Bank.

World Bank (2019). Estimates of population, female $\%$ of Total Population. http://data.worldbank.org/indicator/SP.POP.TOTL.FE.ZS 
Woldu, T., \& Tadesse, F. (2015). Women's Participation in Agricultural Cooperatives in Ethiopia (No. 10082016-80335).

Wrangham, R.T. (2009). Catching Fire: How Cooking Made Us Human. Basic Books, New York.

Yigremew Adal (2001). Land Redistribution and Female, the added Households. A Study in two Rural Communities in Ethiopia, Discussion Papers. Forum for Social Science Studies, AAU.

Yohannes, D. W., \& Endale, N. (2014). Participation of Women in Rural Cooperatives: Evidence from Gewane and Fentale Districts of Afar Region, Ethiopia. Journal of Economics and Sustainable Development, 5(15), $1-8$. 